\title{
Cause specific mortality, social position, and obesity among women who had never smoked: 28 year cohort study
}

\author{
Carole L Hart reader ${ }^{1}$, Laurence Gruer director of public health science ${ }^{2}$, Graham C M Watt professor \\ of general practice ${ }^{3}$
}

${ }^{1}$ Institute of Health and Wellbeing, Public Health, University of Glasgow, Glasgow G12 8RZ, UK; ${ }^{2} \mathrm{NHS}$ Health Scotland, Glasgow, UK; ${ }^{3}$ Institute of Health and Wellbeing, General Practice and Primary Care, University of Glasgow, Glasgow, UK

\begin{abstract}
Objective To investigate the relations between causes of death, social position, and obesity in women who had never smoked.

Design Prospective cohort study.

Setting Renfrew and Paisley, Scotland.

Participants 8353 women and 7049 men aged 45-64 were recruited to the Renfrew and Paisley Study in 1972-6. Of these, 3613 women had never smoked and were the focus of this study. They were categorised by occupational class (I and II, III non-manual, III manual, and IV and V) and body mass index groups (normal weight, overweight, moderately obese, and severely obese).
\end{abstract}

Main outcome measures All cause and cause specific mortality during 28 years of follow-up by occupational class and body mass index, using Cox proportional hazards models adjusted for age and other confounders.

Results The women in lower occupational classes who had never smoked were on average shorter and had poorer lung function and higher systolic blood pressure than women in the higher occupational classes. Overall, $43 \%$ ( $n=1555)$ were overweight, $14 \%(n=515)$ moderately obese, and $5 \%(n=194)$ severely obese. Obesity rates were higher in lower occupational classes and much higher in all occupational classes than in current smokers in the full cohort. Half the women died, $51 \%(n=916)$ from cardiovascular disease and $27 \%(n=487)$ from cancer. Relative to occupational class I and II, all cause mortality rates were more than a third higher in occupational classes III manual (relative rate $1.35,95 \%$ confidence interval 1.16 to 1.57$)$ and IV and $V(1.34,1.17$ to 1.55 ) and largely explained by differences in obesity, systolic blood pressure, and lung function. Similar upward gradients were seen for cardiovascular disease and respiratory disease but not for cancer. Mortality rates were highest in severely obese women in the lowest occupational classes.

Conclusions Women who had never smoked and were not obese had the lowest mortality rates, regardless of their social position. Where obesity is socially patterned as in this cohort, it may contribute to health inequalities and increase pressure on health and social services serving more disadvantaged populations.

\section{Introduction}

Numerous studies have shown that people in lower occupational classes, on lower incomes, or with lower educational attainment have, on average, poorer health. ${ }^{1}$ What causes these consistent differences is complex and may vary according to country or culture. However, in several northern European countries, a noticeable social gradient in smoking rates has developed over the past 50 years as people of higher socioeconomic status have found it easier to stop smoking or to resist the pressures to start. ${ }^{2}$ Research in the United Kingdom has suggested that up to $85 \%$ of the observed differences in mortality between population groups in different social positions can be attributed to smoking. ${ }^{3}$ On the other hand, social inequalities in mortality are relatively low among women in southern European countries, where social inequalities in smoking rates are low. ${ }^{4}$

Using data from a cohort study of adults from Renfrew and Paisley in west central Scotland, we recently found that never smokers had much better survival rates than smokers, regardless of their social position, with women who had never smoked having the best survival rates in the cohort. ${ }^{5}$ Nevertheless, after 28 years of follow-up, age adjusted survival rates for women who had never smoked were $65 \%$ in the highest occupational class and $56 \%$ for those in the lowest. We therefore questioned the relations between causes of death and social position among women who have never smoked. A better understanding could provide a basis for interventions aimed at reducing health inequalities, but an extensive literature search yielded no direct answers. We therefore used data on more than 3600 women in the Renfrew and Paisley Study who had never smoked. In particular we explored further the evidence from this cohort that 
smoking may mask the effects of overweight and obesity on all cause and cause specific mortality. ${ }^{6}$

\section{Methods}

The Renfrew and Paisley Study (one of the Midspan studies) is a long term prospective community based cohort study. It was initiated in 1972 in the neighbouring towns of Renfrew and Paisley in west central Scotland where all residents then aged between 45 and 64 were invited to participate. ${ }^{7}$ In all, 8353 women and 7049 men in this age range were recruited between 1972 and 1976, achieving a participation rate of nearly $80 \%$ of the entire eligible population. The format of the screening was a self completed questionnaire followed by a physical examination, carried out at a temporary clinic set up in community centres across the area. At the screening examination, blood pressure, height, weight, and forced expiratory volume in one second were measured, a non-fasting blood sample was taken for the measurement of plasma cholesterol levels, and a six lead electrocardiogram was taken. ${ }^{8}$ Height and weight were used to calculate body mass index (weight $(\mathrm{kg}) /\left(\right.$ height $\left.(\mathrm{m})^{2}\right)$ ). Overweight and obese were defined according to World Health Organization categories as 25 to $<30$ and $\geq 30$, respectively. The obese category was further subdivided into moderately obese $(30$ to $<35)$ and severely obese $(\geq 35)$. Percentage predicted forced expiratory volume in one second was calculated as actual forced expiratory volume in one second as a percentage of the expected value, which was derived from regression equations using a healthy subset of the cohort. ${ }^{9}$ Ischaemia on electrocardiogram was based on the Minnesota coding system. ${ }^{8}$

The questionnaire included angina status from the Rose chest pain questionnaire, and bronchitis from the Medical Research Council bronchitis questionnaire. ${ }^{111}$ Participants reported their occupation, enabling occupational class to be ascertained based on the registrar general's classification of occupations. ${ }^{12}$ Retired participants gave their last full time occupation. In cases where women classified themselves as housewives, their husband's occupation was used. The six occupational classes were combined to form four groups: occupational classes I and II, III non manual, III manual, and IV and V. Participants answered questions about smoking, enabling women who had never smoked to be selected for this study.

The General Register Office for Scotland provided the dates of death and their causes. We analysed deaths in 28 years of follow-up. The mean follow-up time was 22.7 years. Causes of death, derived from codes in the international classification of diseases ninth and10th revisions were all cause, all cardiovascular disease, coronary heart disease, stroke, respiratory disease, cancer, smoking related cancers, non-smoking related cancers, and breast cancer. Smoking related cancers were cancers of the lip, oral cavity, and pharynx; oesophagus; stomach; liver and intrahepatic bile ducts; pancreas; nasal cavities, middle ear and accessory sinuses; larynx; trachea, bronchus, and lung; pleura; bladder; kidney; and myeloid leukaemia. Non-smoking related cancers were all other cancers.

Overall, 3827 women had never smoked. We excluded seven women who were lost to follow-up, 168 with missing data on occupational class, seven with missing data on body mass index, and 32 who were underweight (body mass index $<18.5$ ).

Analyses were carried out on 3613 women. Missing values for systolic blood pressure $(n=2)$ and cholesterol level $(n=34)$ were added using means for these variables derived from the women who had never smoked. Thirty two women who had never smoked had left the United Kingdom and we censored their survival time at their date of embarkation.

\section{Statistical analysis}

We used Cox's proportional hazards regression models, adjusted for age and other risk factors, to obtain estimates of relative rates of mortality with $95 \%$ confidence intervals, by occupational class and body mass index category, using Stata release 10 . To verify proportional hazards assumptions we inspected Schoenfeld residuals. Using the six occupational classes as a continuous variable we calculated trends across the occupational classes. Analyses by occupational class were first adjusted for age, then for age and body mass index, and finally for all risk factors (age, body mass index, systolic blood pressure, cholesterol level, height, percentage predicted forced expiratory volume in one second, angina, ischaemia on electrocardiogram, and bronchitis for all causes except cancers, which excluded adjustment for the last three). Analyses by body mass index were adjusted for age, then age and occupational class, and finally all risk factors. We tested interactions between occupational class and body mass index and found them to be non-significant for all causes of death. Analyses to ascertain the contribution of risk factors to occupational class differentials in mortality were calculated using occupational class as non-manual (I, II, and III non-manual) and manual (III manual, IV, and V). Compared with the age adjusted model, the percentage reduction attributed to each risk factor was calculated by the formula $100 \times(\beta$ model $-\beta$ model+risk factor $) / \beta$ model.${ }^{13} 14$ A further analysis of all cause mortality placed participants in one of 16 groups depending on their categories of occupational class and body mass index. To analyse the effect of passive smoking of a known co-resident on the relation between occupational class and mortality we used a subgroup of 1913 women who had never smoked and who had complete information on the smoking habit of their co-resident. For the co-resident, we calculated pack years from the number of cigarettes smoked a day and the duration of smoking for former smokers or the duration of smoking to the date of screening for current smokers.

\section{Results}

As the mean age at screening among the 3613 women who had never smoked was higher in those from lower occupational classes, all other risk factors were adjusted for age (table 1). Women in lower occupational classes were on average shorter and had poorer lung function, higher systolic blood pressure, and a higher body mass index than women from the other occupational classes. Body mass index and systolic blood pressure were strongly correlated (correlation coefficient 0.32 , $\mathrm{P}<0.001)$. According to body mass index groups the mean systolic blood pressure ( $\mathrm{mm} \mathrm{Hg}$ ) was 147.8 (95\% confidence interval 146.6 to 149.1 ) in normal weight women, 153.6 (152.4 to 154.8 ) in overweight women, 163.0 (160.8 to 165.2$)$ in moderately obese women, and 174.0 (170.1 to 177.9$)$ in severely obese women. Significantly more women in occupational class IV and $\mathrm{V}$ reported bronchitis than women in occupational class I and II. No clear relations were observed between occupational class and cholesterol level, angina, or ischaemia on electrocardiogram.

Overall, $43 \%(\mathrm{n}=1555)$ of the women who had never smoked were overweight, $14 \%(\mathrm{n}=515)$ were moderately obese, and $5 \%$ $(n=194)$ were severely obese. The body mass indices of the women who had never smoked were compared with those of the 3590 current smokers in the full cohort (table 2). Overweight 
and obesity were more prevalent among never smokers than among current smokers in all occupational classes and among both never smokers and smokers in the lower occupational classes (fig 1). Severe obesity was more than twice as prevalent among women who had never smoked in the lower occupational classes than in women who had never smoked in the higher occupational classes and about seven times more prevalent than among current smokers in the higher occupational classes.

The remainder of the results focus on the 3613 women who had never smoked. In the 28 years of follow-up, 1796 (50\%) women died, with $51 \%$ of the deaths $(\mathrm{n}=916)$ due to cardiovascular disease and $27 \%(\mathrm{n}=487)$ to cancer (table 3$)$. Overall, $270(39 \%)$ women died in occupational class I and II, $434(47 \%)$ in III non-manual, 407 (56\%) in III manual, and 685 (54\%) in IV and $\mathrm{V}$. Upward trends were observed in age adjusted mortality rates with declining occupational class for all causes, cardiovascular disease, coronary heart disease, stroke, and respiratory disease. These were reduced but remained after additional adjustment for body mass index. They also remained when adjustments were made for all risk factors included. Compared with women in occupational class I and II, age adjusted rates were about one third higher in women in occupational classes III manual and IV and V, decreasing to about $20 \%$ higher when adjusted for other risk factors. Age adjusted mortality from coronary heart disease was nearly $60 \%$ higher in occupational class IV and V but this decreased to $32 \%$ after adjustment for other risk factors. Age adjusted mortality rates in occupational class IV and V were higher by $50 \%$ for stroke and by $100 \%$ for respiratory disease, decreasing to higher by $32 \%$ and $78 \%$ after adjustment for other risk factors. Relations between occupational class and mortality rates did not differ significantly for all cancers, smoking related cancers, non-smoking related cancers, or breast cancer.

Among the 1913 women who had never smoked and for whom information was available on smoking habit of co-residents, additional adjustment for co-residents' cigarette pack years had a slight attenuating effect on the age adjusted and the all risk factor adjusted mortality analyses (see web extra table 1).

In an analysis of the three lowest occupational classes (manual) compared with the three highest occupational classes

(non-manual), the age adjusted relative rate for all cause mortality was 1.20 (95\% confidence interval 1.09 to 1.32 ; table 4). The effect of including body mass index in the model was to reduce the association between occupational class and all cause mortality by $23.6 \%$. Including percentage predicted forced expiratory volume in one second reduced the association by $21.8 \%$, and including systolic blood pressure reduced it by $18.9 \%$. Height, bronchitis, ischaemia on electrocardiogram, angina, and cholesterol level led to smaller reductions. All the risk factors explained nearly $64 \%$ of the association.

Upward trends between mortality and increasing body mass index were observed for all cause, cardiovascular disease, coronary heart disease, stroke, and cancer mortality (table 5). Compared with normal weight women, severely obese women had particularly high risks for all cause mortality (relative rate $2.07,95 \%$ confidence interval 1.72 to 2.49 ). Adjustment for occupational class attenuated the relations somewhat, and although adjustment for all the available risk factors caused further attenuation, significant trends remained for all these causes (except stroke). Downward trends were observed between body mass index and mortality due to respiratory disease which strengthened after adjustment. Body mass index showed no clear relation with smoking related cancers, non-smoking related cancers, and breast cancer mortality.
Compared with normal weight women in occupational class I and II, age adjusted all cause mortality rates were not significantly increased among normal weight women in the lower occupational classes (table 6 and fig 2). Mortality rates were increased in the moderately and severely obese women and particularly in women in lower occupational classes. With the exception of women in occupational class I and II, moderately obese women had at least a $60 \%$ increased mortality rate. Severely obese women had around double the mortality rate of normal weight women. Adjustment for other risk factors had a large attenuating effect, but the increased risk in the moderately obese women and particularly in the severely obese women remained.

\section{Discussion}

In this subcohort of women who had never smoked, recruited in 1972-6, we found that those in lower occupational classes had higher mortality rates from cardiovascular disease but not from cancer. Most of the association between occupational class and mortality could be explained by body mass index, systolic blood pressure, and respiratory function. Obesity was more prevalent in never smokers than in the current smokers in the full cohort, with higher prevalence among women in lower social positions, who had higher associated mortality rates. Women who were not obese experienced relatively low mortality rates regardless of their social position.

\section{Strengths and weaknesses of the study}

This study has several important strengths. To our knowledge it is the first to examine the relation between cause specific mortality and social position in women who had never smoked. The women in the study were drawn from a cohort that included almost $80 \%$ of all the 45-64 year olds living in two typical industrial towns in the west of Scotland in 1972-6, a high participation rate. As the participants in the current study were from a general population, the results should be generalisable to other similar populations of the time. Given the increased morbidity and mortality and strong social patterning associated with smoking, the study's focus on women who had never smoked allowed other relations between social position and health to be examined independently. The duration of follow-up was long and the completeness of data excellent, including the categorisation of almost all participants according to their occupational class.

The study has several limitations. Firstly, we can only report health related behaviours and physical measurements such as weight recorded at recruitment. As the women were aged between 45 and 64 at screening, they were unlikely to have taken up smoking in the follow-up period, so we could presume they remained never smokers. Average weight has, however, tended to increase until the seventh decade in the Scottish population. ${ }^{15}$ Consequently, some women with a normal weight at recruitment may have subsequently become overweight or obese but remained classified as being of normal weight in the analysis. Stringhini and colleagues showed that multiple assessments of diet and physical activity over time increased their power to explain subsequent mortality compared with a single initial assessment. ${ }^{14}$ Secondly, because of the long follow-up period from the 1970s the mortality trends may not necessarily reflect the current situation. Comparisons between successive cohorts in the United States suggest the association between obesity and cardiovascular disease mortality has weakened over time, possibly due to improved treatment of related conditions such as hypertension and diabetes. ${ }^{16}$ However, 
this could potentially increase inequalities related to social position if healthcare services are less successfully accessed and used by those in lower social positions. Thirdly, the highest and lowest occupational classes in the study population contained relatively few people. To achieve adequate numbers, we had to amalgamate classes I and II and classes IV and V. Our ability to explore the possible health gradients at the extreme ends of the population was thus limited. Finally, although no questions were asked about ethnicity, the population was almost exclusively white, so the results may not be generalisable to other ethnic groups or mixed populations.

\section{European and Chinese perspectives}

We were unable to find any published studies of mortality and social position in women or men who had never smoked. In a study of women in 22 European countries, using education as a measure of social position, social gradients were much shallower for smoking and steeper for obesity among southern European women compared with their northern and eastern European counterparts. ${ }^{4}$ Among southern European women, those with less education had slightly higher cardiovascular mortality rates but the social gradient for cancer was minimal or even reversed. In terms of their mortality experience, our subcohort of women who had never smoked may thus be closer to southern European women with low levels of smoking ${ }^{17}$ than to their own Scottish neighbours who smoke. ${ }^{17}$ A comparison between French and English cohorts found similar differences in mortality rates between occupational classes in the two cohorts. In the English cohort these were explained to a greater extent by behavioural factors such as smoking, alcohol consumption, and physical activity than in the French cohort. ${ }^{18}$ Body mass index was not, however, included in the analyses. A recent study of Chinese women who had never smoked or consumed alcohol found significant relations between mortality and body mass index, daily exercise, and daily intake of fruit and vegetables after follow-up for nine years. ${ }^{19}$ However, no measures of social position were reported. As no measurements of socially patterned variables such as alcohol consumption, diet, or physical activity were taken in our study, these may have had differential effects on mortality, which we have been unable to detect.

\section{Smoking and obesity}

The higher average body mass indices of never smokers compared with smokers have been highlighted. ${ }^{20-23}$ Our analysis shows higher rates of overweight and obesity among never smokers in all occupational classes, with the highest rates in women from lower occupational classes. Almost $70 \%$ of the women in the lower occupational classes who had never smoked were overweight or obese, among whom severe obesity was seven times more prevalent than among smokers in higher social positions.

Because smokers have on average lower body mass indices but higher mortality rates, it is only when never smokers are analysed separately that the true impact of obesity on mortality becomes clear. We had shown previously that all cause mortality rates were $56 \%$ higher among obese than among normal weight women who had never smoked, with most of the increase attributable to cardiovascular disease. ${ }^{6}$ In the present study, we found only a modest gradient by social position in mortality rates among non-obese women. However, severely obese women in lower social positions had more than double the mortality rates of normal weight women in all social positions. Except for the women in the highest social positions, the differences in mortality rates between non-obese and severely obese women of the same social position were much greater than those between normal or overweight women in different social positions. The four Scottish health surveys of 1995, 1998, 2003, and 2008 showed a steady increase in the prevalence of obesity among Scottish women, ${ }^{15}$ with a small increase in educational inequalities during that period..$^{24}$ Prevalence was much higher than among the women in Renfrew and Paisley examined in $1972-6 .{ }^{15}$ For example, in women aged 55-64, $18 \%$ were obese in the full Renfrew and Paisley cohort, compared with $27 \%$ and $37 \%$ in the Scottish health surveys of 1995 and 2008, respectively. Thus even if the link between obesity and cardiovascular disease mortality has been mitigated by improved clinical management or other factors, ${ }^{16}$ this is likely to have been more than offset by the substantial increase in the overall prevalence of obesity in Scotland, which remained higher among women in lower social positions in 2008. ${ }^{15}$

\section{Respiratory function}

Respiratory function emerged from this analysis as the other main factor explaining the association between occupational class and mortality among the women who had never smoked. The relation between respiratory function and mortality in the Renfrew and Paisley cohort has been the subject of several publications $\mathrm{s}^{25}$ and will be investigated further as a result of this study.

\section{Conclusions and policy implications}

We think these results have important implications. They show that overweight and obesity were already common among women who had never smoked in this population more than 35 years ago, its true extent concealed by the high smoking rates in the population as a whole. They suggest the decline in smoking rates in recent decades may have contributed to the increase in overweight and obesity. Although lifelong smoking is clearly responsible for much higher mortality rates, ${ }^{5}$ obesity, and especially severe obesity, is an important contributor to premature mortality. ${ }^{16}$ The healthcare consequences of increased morbidity from diabetes, hypertension, arthritis, and other complications are also considerable. ${ }^{26}$ If, as in this cohort, obesity is socially patterned, it may add to health inequalities and disproportionately increase the pressure on health and social services serving more disadvantaged populations. On a more positive note, the women in the whole cohort who did not smoke and were not obese had the lowest mortality rates, regardless of their social position. The preventive message is clear.

Victor Hawthorne carried out the original Midspan studies. Pauline MacKinnon is the Midspan administrator.

Contributors: CLH had full access to the data in the study and can take responsibility for the integrity of the data and the accuracy of the data analysis. The other authors had full access to all the results. All authors contributed to the design of the study. CLH analysed the data and wrote the first draft of the manuscript. All authors contributed to the redrafting of the manuscript and approved the final version. CLH is the guarantor.

Funding: This research was supported by NHS Health Scotland. CLH and LG were funded by NHS Health Scotland and GCMW by the University of Glasgow. They had no role in the study design; in the collection, analysis, and interpretation of data; in the writing of the report; and in the decision to submit the article for publication. The researchers were independent of the funders. All decisions relating to the study were made by the authors alone. The views expressed in the paper may not reflect those of the funding organisations.

Competing interests: All authors have completed the ICMJE uniform disclosure form at www.icmje.org/coi_disclosure.pdf (available on 


\section{What is already known on this topic}

Higher smoking rates among people in lower social positions are a known cause of socioeconomic inequalities in health Smokers have lower survival rates than never smokers, regardless of their social position

It is not known which causes of death are related to social position in women who have never smoked

\section{What this study adds}

Among women who had never smoked, lower social position was associated with higher mortality rates from cardiovascular disease but not cancer

Obesity was more prevalent among women in lower social positions and associated with higher mortality rates

Women in this and similar populations who never smoke and are not obese can expect relatively low mortality rates, regardless of their social position

request from the corresponding author) and declare: no support from any organisation for the submitted work; no financial relationships with any organisations that might have an interest in the submitted work in the previous three years; no other relationships or activities that could appear to have influenced the submitted work.

Ethical approval: Not required at the time of the studies.

Data sharing: No additional data available.

1 World Health Organization, Commission on Social Inequalities in Health. Achieving health equity: from root causes to fair outcomes. WHO, 2007.

2 Cavelaars AEJM, Kunst AE, Geurts JJM, Crialesi R, Grotvedt L, Helmert U, et al. Educational differences in smoking: international comparison. BMJ 2000;320:1102-7.

3 Law M, Morris J. Why is mortality higher in poorer areas and in more northern areas in England and Wales? J Epidemiol Community Health 1998;52:344-52.

4 Mackenbach JP, Stirbu I, Roskam AR, Schaap MM, Menvielle G, Leinsalu M, et al. Socioeconomic inequalities in health in 22 European countries. $N$ Engl $J$ Med 2008;358:2468-81.

5 Gruer L, Hart CL, Gordon DS, Watt GCM. Effect of tobacco smoking on survival of men and women by social position: a 28 year cohort study. BMJ 2009;338:b480.

6 Lawlor DA, Hart CL, Hole DJ, Davey Smith G. Reverse causality and confounding and the associations of overweight and obesity with mortality. Obesity 2006;14:2294-304.

7 Hart CL, MacKinnon PL, Watt GCM, Upton MN, McConnachie A, Hole DJ, et al. The Midspan Studies. Int J Epidemiol 2005;34:28-34.

8 Hawthorne VM, Watt GCM, Hart CL, Hole DJ, Davey Smith G, Gillis CR. Cardiorespiratory disease in men and women in urban Scotland: baseline characteristics of the Renfrew/Paisley (Midspan) Study population. Scott Med J 1995;40:102-7.

9 Hole DJ, Watt GCM, Davey Smith G, Hart CL, Gillis CR, Hawthorne VM. Impaired lung function and mortality risk in men and women: findings from the Renfrew and Paisley prospective population study. BMJ 1996;313:711-6.

10 Rose GA. The diagnosis of ischaemic heart pain and intermittent claudication in field surveys. Bull World Health Org 1962;27:645-58.

11 Medical Research Council. Definition and classification of chronic bronchitis for epidemiological purposes. Lancet 1965;i:775-9.

12 General Register Office. Classification of occupations 1966. HMSO, 1966;1-148.
13 Sabia S, Shipley M, Elbaz A, Marmot M, Kivimaki M, Kauffmann F, et al. Why does lung function predict mortality? Results from the Whitehall II cohort study. Am J Epidemiol 2010;172:1415-23

14 Stringhini S, Sabia S, Shipley M, Brunner E, Nabi H, Kivimaki M, et al. Association of socioeconomic position with health behaviors and mortality. JAMA 2010;303:1159-66.

15 Corbett J, Given L, Gray L, Leyland A, MacGregor A, Marryat L, et al. The Scottish Health Survey 2008. 2009. www.scotland.gov.uk/Publications/2009/09/28102003/0.

16 Flegal KM, Graubard BI, Williamson DF, Gail MH. Cause-specific excess deaths associated with underweight, overweight, and obesity. JAMA 2007;298:2028-37.

17 Huisman M, Kunst AE, Mackenbach JP. Educational inequalities in smoking among men and women aged 16 years and older in 11 European countries. Tob Control 2005;14:106-13.

18 Stringhini S, Dugravot A, Shipley M, Goldberg M, Zins M, Kivimaki M, et al. Health behaviours, socioeconomic status, and mortality: further analyses of the British Whitehall II and the French GAZEL prospective cohorts. PLoS Med 2011;8:e1000419.

19 Nechuta SJ, Shu X, LiH, Yang G, Xiang Y, Cai H et al Combined impact of lifestyle-related factors on total and cause-specific mortality among Chinese women: prospective cohort study. PLoS Med 2010;7:e1000339.

20 Dallosso HM, James WPT. The role of smoking in the regulation of energy balance. Int J Obes 1984;8:365-75.

21 Singh PN, Lindsted KD. Body mass and 26-year risk of mortality from specific diseases among women who never smoked. Epidemiology 1998;9:246-54

22 Meyer HE, Sogaard AJ, Tverdal A, Selmer RM. Body mass index and mortality: the influence of physical activity and smoking. Med Sci Sports Exerc 2002;34:1065-70.

23 Aekplakorn W, Chaiyapong Y, Neal B, Chariyalertsak S, Kunanusont C, Phoolcharoen $W$, et al. Prevalence and determinants of overweight and obesity in Thai adults: result of the Second National Health Examination Survey. J Med Assoc Thai 2004;87:685-93.

24 Hotchkiss JW, Davies CA, Gray L, Bromley C, Capewell S, Leyland AH. Socio-economic patterning of the trends in cardiovascular disease risk factors in Scotland: Scottish Health Surveys 1995 to 2008. J Epidemiol Community Health 2010;64:A12-3.

25 Mannino DM, Watt GCM, Hole DJ, Gillis CR, Hart CL, McConnachie A, et al. The natural history of chronic obstructive pulmonary disease. Eur Respir J 2006;27:627-43.

26 Haslam D, Sattar N, Lean M. Obesity-time to wake up. BMJ 2006;333:640-2.

Accepted: 6 May 201

Cite this as: BMJ 2011;342:d3785 


\section{Tables}

Table 1| Age adjusted risk factors by occupational class in $\mathbf{3 6 1 3}$ women from Renfrew and Paisley Study who had never smoked. Values are means (95\% confidence intervals) unless stated otherwise

\begin{tabular}{|c|c|c|c|c|c|}
\hline \multirow[b]{2}{*}{ Variables } & \multicolumn{4}{|c|}{ Occupational classes } & \multirow{2}{*}{$\begin{array}{l}\text { P for trend across all } 6 \\
\text { occupational classes }\end{array}$} \\
\hline & I and II $(n=686)$ & III non-manual $(n=920)$ & III manual $(n=727)$ & IV and $V(n=1280)$ & \\
\hline Age (years) & 54.2 (53.8 to 54.6$)$ & 54.4 (54.1 to 54.8 ) & 56.3 (55.8 to 56.7 ) & 55.7 (55.4 to 56.0$)$ & $<0.001$ \\
\hline Systolic blood pressure $(\mathrm{mm} \mathrm{Hg})$ & 150.3 (148.5 to 152.1$)$ & 152.3 (150.7 to 153.8$)$ & $156.0(154.2$ to 157.9$)$ & 155.7 (154.3 to 157.1$)$ & $<0.001$ \\
\hline Cholesterol level $(\mathrm{mmol} / \mathrm{L})$ & 6.47 (6.39 to 6.55$)$ & 6.60 (6.53 to 6.68$)$ & 6.46 (6.39 to 6.54$)$ & 6.39 (6.33 to 6.45$)$ & 0.001 \\
\hline Height $(\mathrm{cm})$ & 158.7 (158.3 to 159.2$)$ & 158.4 (158.0 to 158.8$)$ & $156.6(156.2$ to 157.1$)$ & 156.4 (156.1 to 156.7$)$ & $<0.001$ \\
\hline$\%$ predicted $\mathrm{FEV}_{1}$ & $101.8(100.0$ to 103.5$)$ & 99.0 (97.6 to 100.4$)$ & 96.0 (94.2 to 97.7$)$ & 92.9 (91.6 to 94.2$)$ & $<0.001$ \\
\hline Body mass index & 25.9 (25.6 to 26.2$)$ & 26.1 (25.9 to 26.4$)$ & $27.6(27.3$ to 28.0$)$ & $27.5(27.2$ to 27.7$)$ & $<0.001$ \\
\hline$\%$ with angina $(95 \% \mathrm{Cl})$ & $7.9(5.8$ to 9.9$)$ & 7.5 (5.8 to 9.2$)$ & 12.2 (9.8 to 14.5$)$ & 8.5 (7.0 to 10.1$)$ & 0.37 \\
\hline$\%$ with ischaemia on ECG $(95 \% \mathrm{Cl})$ & 9.7 (7.4 to 12.0$)$ & $10.7(8.7$ to 12.8$)$ & $13.2(10.7$ to 15.6$)$ & $11.9(10.2$ to 13.7$)$ & 0.09 \\
\hline$\%$ with bronchitis $(95 \% \mathrm{Cl})$ & $0.8(0.2$ to 1.5$)$ & 1.5 (0.7 to 2.3$)$ & 2.5 (1.3 to 3.6$)$ & 2.9 (2.0 to 3.9$)$ & 0.002 \\
\hline
\end{tabular}

$\mathrm{FEV}_{1}=$ forced expiratory volume in one second; $E C G=$ electrocardiogram. 
Table 2| Age adjusted proportions of overweight, obese, moderately obese, and severely obese by occupational class in 3613 women who had never smoked and 3590 women who were current smokers from Renfrew and Paisley Study. Values are percentages (95\% Cls) unless stated otherwise

\begin{tabular}{|c|c|c|c|c|c|}
\hline \multirow[b]{2}{*}{ Variables } & \multicolumn{4}{|c|}{ Occupational classes } & \multirow[b]{2}{*}{ P for trend across all 6 occupational classes } \\
\hline & I and II & III non-manual & III manual & IV and V & \\
\hline \multicolumn{6}{|l|}{ Never smokers: } \\
\hline No of women & 686 & 920 & 727 & 1280 & \\
\hline Overweight & 40.3 (36.6 to 44.1$)$ & 40.7 (37.5 to 43.9$)$ & 44.7 (41.0 to 48.4$)$ & $44.9(42.2$ to 47.6$)$ & 0.031 \\
\hline Obese & $13.3(10.7$ to 15.9$)$ & $15.2(12.8$ to 17.5$)$ & 24.1 (20.9 to 27.2$)$ & $23.7(21.4$ to 26.0$)$ & $<0.001$ \\
\hline Moderately obese* & 9.9 (7.5 to 12.2$)$ & 12.1 (10.0 to 14.2$)$ & $16.4(13.7$ to 19.1$)$ & $16.8(14.8$ to 18.8$)$ & $<0.001$ \\
\hline Severely obese† & $3.4(2.0$ to 4.9$)$ & $3.1(1.9$ to 4.3$)$ & $7.7(5.7$ to 9.7$)$ & $6.9(5.5$ to 8.3$)$ & $<0.001$ \\
\hline \multicolumn{6}{|l|}{ Current smokers: } \\
\hline No of women & 603 & 837 & 634 & 1516 & \\
\hline Overweight & 29.0 (25.4 to 32.6$)$ & 29.7 (26.6 to 32.9$)$ & 33.2 (29.5 to 36.9 ) & 34.3 (31.9 to 36.7 ) & 0.001 \\
\hline Obese & $9.5(7.1$ to 11.8$)$ & 8.1 (6.2 to 9.9$)$ & 12.2 (9.7 to 14.8 ) & 13.1 (11.4 to 14.8$)$ & $<0.001$ \\
\hline Moderately obese* & $8.3(6.1$ to 10.5$)$ & 7.0 (5.3 to 8.8$)$ & 9.6 (7.3 to 11.8$)$ & $9.8(8.3$ to 11.3$)$ & 0.05 \\
\hline Severely obese $†$ & $1.2(0.3$ to 2.0$)$ & $1.0(0.4$ to 1.7$)$ & 2.7 (1.5 to 3.9$)$ & 3.3 (2.4 to 4.2$)$ & $<0.001$ \\
\hline
\end{tabular}

*Body mass index 30 to $<35$.

†Body mass index $\geq 35$. 
Table 3| Age and all risk factor adjusted relative rates of mortality by occupational class in $\mathbf{3 6 1 3}$ women from Renfrew and Paisley Study who had never smoked

\begin{tabular}{|c|c|c|c|c|c|}
\hline \multirow[b]{2}{*}{ Variables } & \multicolumn{4}{|c|}{ Occupational classes } & \multirow{2}{*}{$\begin{array}{l}P \text { for trend } \\
\text { across all } 6 \\
\text { occupational } \\
\text { classes }\end{array}$} \\
\hline & $(\mathrm{n}=686)$ & III non-manual $(n=920)$ & III manual ( $n=727)$ & IV and V $(n=1280)$ & \\
\hline \multicolumn{6}{|l|}{ All cause mortality: } \\
\hline No of deaths & 270 & 434 & 407 & 685 & \\
\hline Relative rate* $(95 \% \mathrm{Cl})$ & 1 & 1.21 (1.04 to 1.41$)$ & 1.35 (1.16 to 1.57$)$ & 1.34 (1.17 to 1.55$)$ & $<0.001$ \\
\hline Relative rate† $(95 \% \mathrm{Cl})$ & 1 & $1.21(1.04$ to 1.41$)$ & 1.30 (1.11 to 1.52$)$ & 1.29 (1.12 to 1.48$)$ & 0.001 \\
\hline Relative rateł $(95 \% \mathrm{Cl})$ & 1 & 1.22 (1.05 to 1.42$)$ & $1.22(1.04$ to 1.43$)$ & 1.19 (1.03 to 1.38$)$ & 0.059 \\
\hline \multicolumn{6}{|l|}{ Cardiovascular disease: } \\
\hline No of deaths & 132 & 200 & 210 & 374 & \\
\hline Relative rate $^{*}(95 \% \mathrm{Cl})$ & 1 & $1.14(0.91$ to 1.41$)$ & 1.36 (1.09 to 1.69$)$ & 1.46 (1.20 to 1.78$)$ & $<0.001$ \\
\hline Relative rate $\nmid(95 \% \mathrm{Cl})$ & 1 & 1.14 (0.91 to 1.42$)$ & $1.29(1.04$ to 1.61$)$ & 1.38 (1.13 to 1.68$)$ & 0.001 \\
\hline Relative rateł $(95 \% \mathrm{Cl})$ & 1 & 1.14 (0.91 to 1.42$)$ & $1.17(0.94$ to 1.46$)$ & 1.24 (1.01 to 1.52$)$ & 0.038 \\
\hline \multicolumn{6}{|l|}{ Coronary heart disease: } \\
\hline No of deaths & 68 & 104 & 99 & 205 & \\
\hline Relative rate $^{*}(95 \% \mathrm{Cl})$ & 1 & 1.15 (0.85 to 1.56$)$ & 1.28 (0.94 to 1.74$)$ & 1.57 (1.20 to 2.07$)$ & 0.001 \\
\hline Relative rate† $(95 \% \mathrm{Cl})$ & 1 & $1.16(0.85$ to 1.57$)$ & 1.20 (0.88 to 1.64$)$ & $1.47(1.12$ to 1.94$)$ & 0.007 \\
\hline Relative rate $\neq(95 \% \mathrm{Cl})$ & 1 & 1.12 (0.82 to 1.52$)$ & 1.07 (0.78 to 1.46$)$ & $1.32(0.99$ to 1.74$)$ & 0.07 \\
\hline \multicolumn{6}{|l|}{ Stroke: } \\
\hline No of deaths & 42 & 65 & 83 & 124 & \\
\hline Relative rate $^{*}(95 \% \mathrm{Cl})$ & 1 & $1.16(0.78$ to 1.70$)$ & 1.61 (1.11 to 2.34 ) & 1.50 (1.05 to 2.13$)$ & 0.002 \\
\hline Relative rate $(95 \% \mathrm{Cl})$ & 1 & 1.14 (0.78 to 1.69$)$ & 1.59 (1.09 to 2.31$)$ & 1.45 (1.02 to 2.07$)$ & 0.006 \\
\hline Relative rate $\neq(95 \% \mathrm{Cl})$ & 1 & 1.17 (0.79 to 1.73$)$ & 1.47 (1.01 to 2.15$)$ & 1.32 (0.93 to 1.89$)$ & 0.05 \\
\hline \multicolumn{6}{|l|}{ Respiratory disease: } \\
\hline No of deaths & 16 & 23 & 32 & 62 & \\
\hline 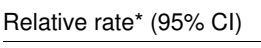 & 1 & 1.07 (0.57 to 2.03$)$ & $1.66(0.91$ to 3.04$)$ & 2.0 (1.15 to 3.46$)$ & 0.001 \\
\hline Relative rate $(95 \% \mathrm{Cl})$ & 1 & 1.06 (0.56 to 2.01$)$ & 1.74 (0.95 to 3.19$)$ & 2.10 (1.21 to 3.64$)$ & 0.001 \\
\hline Relative rate $\neq(95 \% \mathrm{Cl})$ & 1 & $1.11(0.58$ to 2.10$)$ & 1.58 (0.86 to 2.90$)$ & 1.78 (1.02 to 3.12$)$ & 0.012 \\
\hline \multicolumn{6}{|l|}{ Cancer: } \\
\hline No of deaths & 78 & 147 & 104 & 158 & \\
\hline 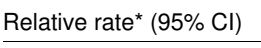 & 1 & 1.44 (1.09 to 1.89$)$ & $1.30(0.97$ to 1.75$)$ & 1.13 (0.86 to 1.48$)$ & 0.96 \\
\hline Relative rate† $(95 \% \mathrm{Cl})$ & 1 & 1.44 (1.09 to 1.89$)$ & 1.26 (0.93 to 1.69$)$ & 1.09 (0.83 to 1.43 ) & 0.68 \\
\hline Relative rate§ $(95 \% \mathrm{Cl})$ & 1 & 1.46 (1.11 to 1.92$)$ & $1.26(0.93$ to 1.69$)$ & 1.08 (0.82 to 1.42$)$ & 0.58 \\
\hline \multicolumn{6}{|l|}{ Smoking related cancers: } \\
\hline No of deaths & 24 & 36 & 35 & 48 & \\
\hline 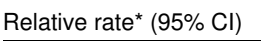 & 1 & 1.15 (0.68 to 1.92$)$ & $1.46(0.87$ to 2.46$)$ & 1.14 (0.69 to 1.86$)$ & 0.71 \\
\hline Relative rate $\nmid(95 \% \mathrm{Cl})$ & 1 & $1.16(0.69$ to 1.94$)$ & $1.39(0.82$ to 2.35$)$ & $1.09(0.67$ to 1.79$)$ & 0.90 \\
\hline Relative rate§ $(95 \% \mathrm{Cl})$ & 1 & $1.17(0.70$ to 1.97$)$ & 1.34 (0.79 to 2.28$)$ & 1.04 (0.63 to 1.72 ) & 0.89 \\
\hline \multicolumn{6}{|c|}{ Non-smoking related cancers: } \\
\hline No of deaths & 54 & 111 & 69 & 110 & \\
\hline Relative rate $^{*}(95 \% \mathrm{Cl})$ & 1 & 1.56 (1.13 to 2.16$)$ & $1.23(0.86$ to 1.77$)$ & $1.13(0.81$ to 1.56$)$ & 0.76 \\
\hline Relative rate $(95 \% \mathrm{Cl})$ & 1 & 1.56 (1.13 to 2.16$)$ & $1.20(0.83$ to 1.71$)$ & 1.09 (0.78 to 1.51$)$ & 0.56 \\
\hline Relative rate§ $(95 \% \mathrm{Cl})$ & 1 & 1.59 (1.15 to 2.20$)$ & 1.21 (0.85 to 1.74$)$ & 1.09 (0.78 to 1.52$)$ & 0.57 \\
\hline \multicolumn{6}{|l|}{ Breast cancer: } \\
\hline No of deaths & 15 & 33 & 16 & 29 & \\
\hline Relative rate* $(95 \% \mathrm{Cl})$ & 1 & 1.67 (0.91 to 3.08$)$ & $1.03(0.51$ to 2.10$)$ & $1.07(0.57$ to 2.0$)$ & 0.51 \\
\hline Relative rate $+(95 \% \mathrm{Cl})$ & 1 & $1.66(0.90$ to 3.07$)$ & 1.03 (0.51 to 2.11$)$ & 1.06 (0.57 to 1.99$)$ & 0.52 \\
\hline Relative rate§ $(95 \% \mathrm{Cl})$ & 1 & 1.66 (0.90 to 3.07$)$ & 1.02 (0.50 to 2.08$)$ & 1.04 (0.55 to 1.97$)$ & 0.49 \\
\hline
\end{tabular}


Table 3 (continued)

\begin{tabular}{|c|c|c|c|c|}
\hline \multirow[b]{2}{*}{ Variables } & \multicolumn{3}{|c|}{ Occupational classes } & \multirow{2}{*}{$\begin{array}{c}\text { P for trend } \\
\text { across all } 6 \\
\text { occupational } \\
\text { classes }\end{array}$} \\
\hline & $(n=686)$ & III non-manual $(n=920)$ & III manual (n=727) & \\
\hline
\end{tabular}

${ }^{*}$ Adjusted for age.

†Adjusted for age and body mass index.

$\ddagger$ Adjusted for age, body mass index, systolic blood pressure, cholesterol level, height, percentage predicted forced expiratory volume in one second, angina, ischaemia on electrocardiogram, and bronchitis.

$\S$ Adjusted for age, body mass index, systolic blood pressure, cholesterol level, height, and percentage predicted forced expiratory volume in one second. 
Table 4| Role of risk factors in explaining association between occupational class (manual v non-manual) and all cause mortality in 3613 women from Renfrew and Paisley Study who had never smoked

\begin{tabular}{lcc} 
Risk factors included in adjustment & Relative rate ${ }^{\star}(95 \%$ Cl) & \% reduction $\dagger$ \\
\hline Age alone (model 1$)$ & $1.20(1.09$ to 1.32$)$ & \\
\hline Risk factors included in model: & & 23.6 \\
\hline Body mass index & $1.15(1.04$ to 1.27$)$ & 21.8 \\
\hline \% predicted FEV & $1.15(1.05$ to 1.27$)$ & 18.9 \\
\hline Systolic blood pressure & $1.16(1.05$ to 1.28$)$ & 9.3 \\
\hline Height & $1.18(1.07$ to 1.30$)$ & 6.7 \\
\hline Bronchitis & $1.19(1.08$ to 1.31$)$ & 6.3 \\
\hline Ischaemia on ECG & $1.19(1.08$ to 1.31$)$ & 3.2 \\
\hline Angina & $1.19(1.09$ to 1.31$)$ & 1.5 \\
\hline Cholesterol level & $1.20(1.09$ to 1.32$)$ & 63.9 \\
\hline All risk factors & $1.07(0.97$ to 1.18$)$ & \\
\hline
\end{tabular}

$\mathrm{FEV}_{1}=$ forced expiratory volume in one second; $\mathrm{ECG}=$ electrocardiogram.

*Occupational classes III manual, IV, and V compared with occupational classes I, II, and III non-manual.

†Using formula $100 \times(\beta$ model $1-\beta$ model $1+$ risk factor $) / \beta$ model 1. 
Table 5 Age and all risk factor adjusted relative rates of mortality by body mass index in $\mathbf{3 6 1 3}$ women from Renfrew and Paisley Study who had never smoked

\begin{tabular}{|c|c|c|c|c|c|}
\hline \multirow[b]{2}{*}{ Variables } & \multicolumn{4}{|c|}{ Body mass index } & \multirow{2}{*}{$\begin{array}{l}\text { P for trend by } \\
\text { body mass } \\
\text { index }\end{array}$} \\
\hline & $\begin{array}{c}\text { Normal weight } \\
(n=1349)\end{array}$ & Overweight ( $n=1555)$ & Moderately obese $(n=515)$ & Severely obese $(n=194)$ & \\
\hline \multicolumn{6}{|l|}{ All cause mortality: } \\
\hline No of deaths & 582 & 771 & 299 & 144 & \\
\hline Relative rate* $(95 \% \mathrm{Cl})$ & 1 & $1.12(1.01$ to 1.25$)$ & $1.39(1.21$ to 1.60$)$ & 2.07 (1.72 to 2.49$)$ & $<0.001$ \\
\hline Relative rate $(95 \% \mathrm{Cl})$ & 1 & 1.10 (0.99 to 1.23$)$ & 1.35 (1.17 to 1.56$)$ & 2.01 (1.67 to 2.42 ) & $<0.001$ \\
\hline Relative rate $\neq(95 \% \mathrm{Cl})$ & 1 & 1.02 (0.92 to 1.14$)$ & 1.13 (0.98 to 1.31$)$ & 1.56 (1.29 to 1.89$)$ & $<0.001$ \\
\hline \multicolumn{6}{|l|}{ Cardiovascular disease: } \\
\hline No of deaths & 277 & 384 & 168 & 87 & \\
\hline Relative rate* $(95 \% \mathrm{Cl})$ & 1 & 1.14 (0.98 to 1.33$)$ & 1.59 (1.31 to 1.92$)$ & 2.53 (1.99 to 3.23$)$ & $<0.001$ \\
\hline Relative rate $(95 \% \mathrm{Cl})$ & 1 & $1.11(0.95$ to 1.30$)$ & $1.52(1.25$ to 1.85$)$ & 2.42 (1.89 to 3.08$)$ & $<0.001$ \\
\hline Relative rate $\neq(95 \% \mathrm{Cl})$ & 1 & 0.99 (0.84 to 1.15$)$ & 1.15 (0.94 to 1.41$)$ & 1.69 (1.31 to 2.18$)$ & $<0.001$ \\
\hline \multicolumn{6}{|l|}{ Coronary heart disease: } \\
\hline No of deaths & 138 & 208 & 82 & 48 & \\
\hline Relative rate* $(95 \% \mathrm{Cl})$ & 1 & $1.26(1.01$ to 1.56$)$ & 1.57 (1.19 to 2.07$)$ & 2.79 (2.01 to 3.88 ) & $<0.001$ \\
\hline Relative rate $(95 \% \mathrm{Cl})$ & 1 & 1.22 (0.98 to 1.52$)$ & 1.50 (1.14 to 1.97$)$ & 2.65 (1.90 to 3.70$)$ & $<0.001$ \\
\hline Relative rateł $(95 \% \mathrm{Cl})$ & 1 & 1.08 (0.87 to 1.34$)$ & $1.08(0.82$ to 1.44$)$ & 1.89 (1.34 to 2.68$)$ & 0.004 \\
\hline \multicolumn{6}{|l|}{ Stroke: } \\
\hline No of deaths & 110 & 117 & 59 & 28 & \\
\hline Relative rate* $(95 \% \mathrm{Cl})$ & 1 & 0.85 (0.65 to 1.10$)$ & $1.37(1.0$ to 1.89$)$ & 2.03 (1.34 to 3.09$)$ & $<0.001$ \\
\hline Relative rate $(95 \% \mathrm{Cl})$ & 1 & 0.81 (0.62 to 1.06 ) & 1.30 (0.95 to 1.79$)$ & 1.91 (1.25 to 2.90$)$ & 0.002 \\
\hline Relative rate $\neq(95 \% \mathrm{Cl})$ & 1 & 0.72 (0.55 to 0.95$)$ & 1.02 (0.73 to 1.42$)$ & 1.26 (0.81 to 1.96$)$ & 0.38 \\
\hline \multicolumn{6}{|l|}{ Respiratory disease: } \\
\hline No of deaths & 57 & 54 & 18 & 4 & \\
\hline Relative rate* $(95 \% \mathrm{Cl})$ & 1 & 0.77 (0.53 to 1.11$)$ & 0.83 (0.49 to 1.41$)$ & 0.60 (0.22 to 1.66$)$ & 0.25 \\
\hline Relative rate $(95 \% \mathrm{Cl})$ & 1 & 0.71 (0.48 to 1.03 ) & 0.74 (0.43 to 1.26$)$ & 0.53 (0.19 to 1.47$)$ & 0.10 \\
\hline Relative rate $\neq(95 \% \mathrm{Cl})$ & 1 & 0.63 (0.43 to 0.92$)$ & 0.59 (0.34 to 1.03$)$ & $0.33(0.12$ to 0.95$)$ & 0.009 \\
\hline \multicolumn{6}{|l|}{ Cancer: } \\
\hline No of deaths & 164 & 222 & 71 & 30 & \\
\hline Relative rate* $(95 \% \mathrm{Cl})$ & 1 & 1.19 (0.97 to 1.46$)$ & 1.22 (0.92 to 1.61$)$ & 1.58 (1.07 to 2.33$)$ & 0.029 \\
\hline Relative rate† $(95 \% \mathrm{Cl})$ & 1 & 1.20 (0.98 to 1.48$)$ & 1.24 (0.94 to 1.64$)$ & 1.61 (1.09 to 2.39$)$ & 0.022 \\
\hline Relative rate§ $(95 \% \mathrm{Cl})$ & 1 & $1.22(0.99$ to 1.50$)$ & 1.29 (0.96 to 1.72$)$ & 1.61 (1.07 to 2.42$)$ & 0.017 \\
\hline \multicolumn{6}{|l|}{ Smoking related cancers: } \\
\hline No of deaths & 43 & 76 & 14 & 10 & \\
\hline Relative rate* $(95 \% \mathrm{Cl})$ & 1 & 1.57 (1.08 to 2.28$)$ & 0.94 (0.51 to 1.72 ) & 2.10 (1.05 to 4.19$)$ & 0.11 \\
\hline Relative rate† $(95 \% \mathrm{Cl})$ & 1 & 1.55 (1.06 to 2.26$)$ & $0.93(0.50$ to 1.70$)$ & 2.05 (1.02 to 4.11$)$ & 0.14 \\
\hline Relative rate§ $(95 \% \mathrm{Cl})$ & 1 & 1.51 (1.03 to 2.20$)$ & 0.88 (0.47 to 1.63 ) & 1.74 (0.85 to 3.60$)$ & 0.33 \\
\hline \multicolumn{6}{|c|}{ Non-smoking related cancers: } \\
\hline No of deaths & 121 & 146 & 57 & 20 & \\
\hline Relative rate* $(95 \% \mathrm{Cl})$ & 1 & $1.06(0.83$ to 1.34$)$ & $1.32(0.96$ to 1.81$)$ & $1.40(0.87$ to 2.24$)$ & 0.12 \\
\hline Relative rate $(95 \% \mathrm{Cl})$ & 1 & 1.08 (0.85 to 1.38$)$ & 1.35 (0.98 to 1.86$)$ & $1.46(0.90$ to 2.35$)$ & 0.08 \\
\hline Relative rate§ $(95 \% \mathrm{Cl})$ & 1 & $1.12(0.87$ to 1.43$)$ & $1.46(1.05$ to 2.03$)$ & 1.55 (0.95 to 2.54$)$ & 0.029 \\
\hline \multicolumn{6}{|l|}{ Breast cancer: } \\
\hline No of deaths & 35 & 41 & 15 & 2 & \\
\hline Relative rate* $(95 \% \mathrm{Cl})$ & 1 & $1.03(0.65$ to 1.61$)$ & 1.19 (0.65 to 2.19$)$ & $0.47(0.11$ to 1.97$)$ & 0.81 \\
\hline Relative rate $(95 \% \mathrm{Cl})$ & 1 & 1.06 (0.67 to 1.68$)$ & 1.25 (0.68 to 2.29$)$ & 0.51 (0.12 to 2.14$)$ & 0.96 \\
\hline Relative rate§ $(95 \% \mathrm{Cl})$ & 1 & $1.06(0.67$ to 1.68$)$ & $1.26(0.67$ to 2.37$)$ & 0.52 (0.12 to 2.22$)$ & 0.995 \\
\hline
\end{tabular}


Table 5 (continued)

\begin{tabular}{|c|c|c|c|c|}
\hline \multirow[b]{2}{*}{ Variables } & \multicolumn{3}{|c|}{ Body mass index } & \multirow{2}{*}{$\begin{array}{l}P \text { for trend by } \\
\text { body mass } \\
\text { index }\end{array}$} \\
\hline & $\begin{array}{l}\text { Normal weight } \\
\quad(n=1349)\end{array}$ & Moderately obese $(n=515)$ & Severely obese $(n=194)$ & \\
\hline
\end{tabular}

${ }^{*}$ Adjusted for age.

†Adjusted for age and occupational class.

$\ddagger$ Adjusted for age, occupational class, systolic blood pressure, cholesterol level, height, percentage predicted forced expiratory volume in one second, angina,

ischaemia on electrocardiogram, and bronchitis.

§Adjusted for age, occupational class, systolic blood pressure, cholesterol level, height, and percentage predicted forced expiratory volume in one second. 
Table 6 | Age and all risk factor adjusted relative rates of all cause mortality in 3613 women from Renfrew and Paisley Study who had never smoked by body mass index and occupational class

\begin{tabular}{|c|c|c|c|c|}
\hline \multirow[b]{2}{*}{ Variables } & \multicolumn{4}{|c|}{ Occupational class } \\
\hline & I and II & III non-manual & III manual & IV and V \\
\hline \multicolumn{5}{|l|}{ Normal weight: } \\
\hline No of women (No dead) & $322(120)$ & $408(170)$ & $222(116)$ & $397(176)$ \\
\hline Relative rate $^{*}(95 \% \mathrm{Cl})$ & 1 & 1.03 (0.81 to 1.30$)$ & 1.26 (0.98 to 1.63$)$ & $1.14(0.90$ to 1.44$)$ \\
\hline Relative rate† $(95 \% \mathrm{Cl})$ & 1 & $1.02(0.81$ to 1.29$)$ & $1.21(0.94$ to 1.57$)$ & 1.06 (0.84 to 1.33$)$ \\
\hline \multicolumn{5}{|l|}{ Overweight: } \\
\hline No of women (No dead) & $277(107)$ & $375(183)$ & $327(174)$ & $576(307)$ \\
\hline Relative rate $(95 \% \mathrm{Cl})$ & 0.96 (0.74 to 1.25$)$ & 1.33 (1.06 to 1.67$)$ & 1.19 (0.95 to 1.51$)$ & 1.31 (1.06 to 1.62$)$ \\
\hline Relative rate $(95 \% \mathrm{Cl})$ & 0.89 (0.68 to 1.15$)$ & 1.23 (0.97 to 1.55$)$ & 1.05 (0.83 to 1.33$)$ & $1.14(0.92$ to 1.41$)$ \\
\hline \multicolumn{5}{|l|}{ Moderately obese: } \\
\hline No of women (No dead) & $65(26)$ & $110(64)$ & $122(74)$ & $218(135)$ \\
\hline Relative rate* $(95 \% \mathrm{Cl})$ & 0.95 (0.62 to 1.45$)$ & 1.57 (1.16 to 2.13 ) & 1.73 (1.29 to 2.31$)$ & 1.57 (1.23 to 2.01$)$ \\
\hline Relative rate† $(95 \% \mathrm{Cl})$ & 0.81 (0.53 to 1.24$)$ & $1.40(1.03$ to 1.90$)$ & 1.31 (0.97 to 1.76$)$ & 1.22 (0.95 to 1.57$)$ \\
\hline \multicolumn{5}{|l|}{ Severely obese: } \\
\hline No of women (No dead) & $22(17)$ & $27(17)$ & $56(43)$ & $89(67)$ \\
\hline Relative rate* $(95 \% \mathrm{Cl})$ & 2.05 (1.23 to 3.41$)$ & 1.68 (1.01 to 2.79 ) & 2.53 (1.78 to 3.59 ) & 2.40 (1.78 to 3.23$)$ \\
\hline Relative rate $(95 \% \mathrm{Cl})$ & 1.64 (0.99 to 2.74$)$ & 1.37 (0.82 to 2.29 ) & 1.84 (1.28 to 2.63$)$ & 1.69 (1.24 to 2.31$)$ \\
\hline
\end{tabular}

*Adjusted for age.

†Adjusted for age, systolic blood pressure, cholesterol level, height, \% predicted forced expiratory volume in one second, angina, ischaemia on electrocardiogram, and bronchitis. 


\section{Figures}

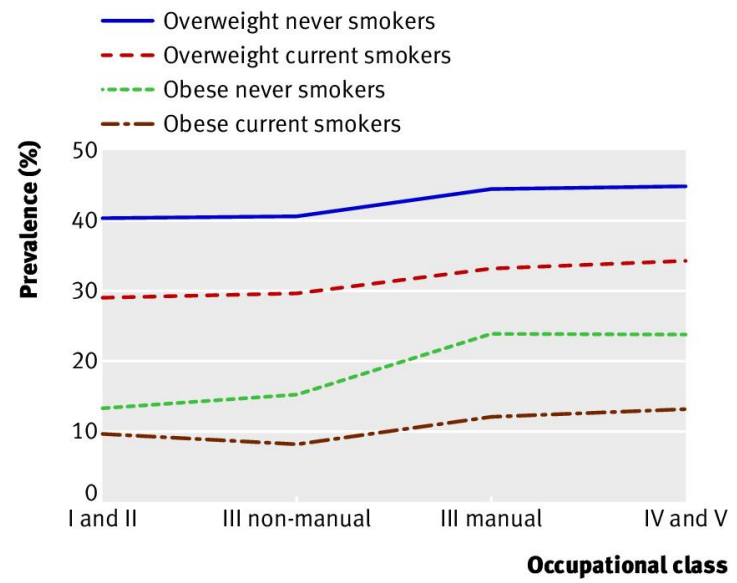

Fig 1 Overweight and obesity among women who had never smoked and current smokers by occupational class

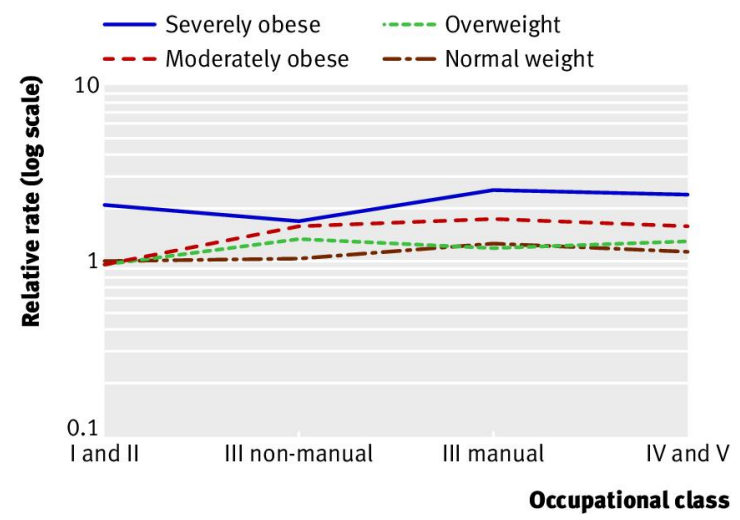

Fig 2 Age adjusted relative mortality rates by occupational class and body mass index groups in women from Renfrew and Paisley Study who had never smoked, with normal weight women in occupational class I and II as baseline group 